\title{
TRIPS, bilateralismo e patentes: o desapontamento dos mundos desenvolvido e em desenvolvimento e o que fazer
}

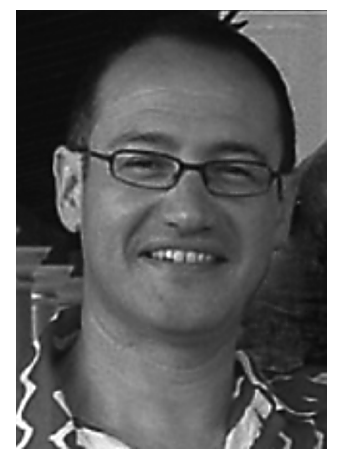

\section{Luigi Palombi}

Centre for Governance of Knowledge and Development, Regulatory Institutions Network, College of Asia and the Pacific, The Australian National University, Camberra, Austrália

luigi.palombi@anu.edu.au

\section{Resumo}

A grande maioria dos recursos biológicos mundiais e do conhecimento tradicional está localizada no mundo em desenvolvimento, embora a grande maioria da propriedade intelectual do mundo sobre biotecnologia seja propriedade do mundo desenvolvido. Desde a formação da OMC, o mundo em desenvolvimento apóia as demandas do mundo desenvolvido relativas a uma maior proteção da propriedade intelectual. No entanto, como agora ele busca apoio do mundo desenvolvido para explorar esses recursos, descobre que o mundo desenvolvido somente respondeu com propostas de bilateralismo. Além disso, o aumento do investimento externo direto esperado não se concretizou, ainda que tenha continuado a fluir para a China, um país que é o maior produtor mundial de mercadorias falsificadas. Este artigo discute o TRIPS ${ }^{1}$ [Acordo sobre Aspectos dos Direitos de Propriedade Intelectual relacionados ao Comércio], o bilateralismo pós-TRIPS e as patentes no contexto dos recursos biológicos e do conhecimento tradicional e busca apresentar uma solução para o impasse atual da propriedade intelectual entre os países desenvolvidos e aqueles em desenvolvimento.

\section{Palavras-chave}

TRIPS, conhecimento tradicional, patentes, sui generis, bilateralismo

\section{TRIPS}

No final do século XX e início do XXI, a colaboração entre duas das economias mais expressivas do mundo - a dos Estados Unidos (EU) e a da União Européia (UE), não poderia ser maior do que a que se refere à propriedade intelectual. Em primeiro lugar, com a Rodada Uruguai do GATT $^{2}$ em Punta del Este, em setembro de 1986, a propriedade intelectual foi por eles priorizada supostamente "para garantir que medidas e procedimentos com o objetivo de fazer cumprir os direitos de propriedade intelectual não se tornem barreiras para o comércio justo". ${ }^{3}$ Apesar dos protestos do Brasil, da Índia, Argentina, Tailândia e outros países em desenvolvimento, a questão da propriedade intelectual, que até então tinha sido considerada apenas no contexto da falsificação de mercadorias com marca registrada ${ }^{4}$, de repente foi ampliada para incluir todas as suas formas no contexto do GATT.

Enquanto o impulso direcionado para esse movimento veio, primeiro, de uma colaboração difusa entre os países desenvolvidos, entre eles, Estados Unidos, Suíça, Japão, os da União Européia, Finlândia e Noruega, “a centelha que acendeu o trabalho rumo ao Acordo TRIPS" 
(GERVAIS, 2003) de fato veio da União Européia, em março de 1990, sob a forma do Draft Agreement on TradeRelated Aspects of Intellectual Property Rights [Esboço para Acordo sobre Aspectos dos Direitos de Propriedade Intelectual Relacionados ao Comércio]. Em uma abordagem aparentemente insensível à furiosa controvérsia entre os países do Norte e do Sul sobre a adequação da propriedade intelectual às negociações comerciais, a União Européia deu seu passo decisivo inesperadamente, pegando os Estados Unidos praticamente de surpresa. Em dois meses, os Estados Unidos fizeram também seu próprio esboço ${ }^{5}$ para um acordo com uma linguagem tão semelhante, que Daniel Gervais conjecturou ser produto de "consultas transatlânticas" (GERVAIS, 2003). Ao produzir o que era quase uma imagem espelhada do esboço da União Européia, os Estados Unidos e a União Européia não só articularam eventos para permiti-los controlar a agenda, o debate, e o rascunho do que finalmente ficou conhecido como Agreement on Trade-Related Aspects of Intellectual Property [Acordo sobre Aspectos dos Direitos de Propriedade Intelectual Relacionados ao Comércio] ou TRIPS ${ }^{6}$, mas também convenceram tanto países desenvolvidos ${ }^{7}$ quanto um número significativo de países em desenvolvimento ${ }^{8}$, entre os quais muitos tinham, apenas cinco anos antes, resistido fortemente à idéia de incorporar a propriedade intelectual às negociações de um comércio multilateral, a assinarem o TRIPS em 15 de abril de 1994. No dia $1^{\circ}$ de janeiro de 1995, o TRIPS como um dos acordos-chave da OMC, organização internacional que atualmente tem cento e cinqüenta membros, entrou em vigor.

Por que os Estados Unidos e a União Européia foram tão convincentes em um espaço de tempo tão curto deixou muitos observadores perplexos, principalmente, como observou Peter Drahos, porque "do ponto de vista do comércio imediato, a globalização da propriedade intelectual realmente só beneficiou os Estados Unidos e em menor medida a Comunidade Européia" (DRAHOS, 2003). No entanto, desde sua instituição, não só os membros da OMC cresceram significativamente ${ }^{9}$, como hoje ela inclui a China que, de acordo com as últimas estatísticas da Organização Mundial da Propriedade Intelectual (OMPI $\left.{ }^{10}\right)$, desalojou a Suíça para se tornar o oitavo maior país em matéria de registro de patentes internacionais, com um aumento de $57 \%$ nos registros do Tratado de Cooperação em Matéria de Patentes (PCT ${ }^{11}$ ) entre 2005 e 2006 (WIPO, 2007). Na verdade, segundo a OMPI, durante o mesmo período, os pedidos de patentes internacionais feitos pelos países em desenvolvimento ${ }^{12}$ aumentaram quase $28 \%$.

O que essas estatísticas da OMPI sugerem é que a OMC (ou seja, GATT + TRIPS) tem sido eficaz na promoção do reconhecimento mútuo, da proteção e implementação da propriedade intelectual tanto nos países desenvolvidos como naqueles em desenvolvimento e, tem um papel importante ao estimular esses últimos a estabelecerem sua própria capacidade de criação de propriedade intelectual dos nativos, especialmente na forma de patentes. Esse crescimento de registros de patentes internacionais levaram o dr. Francis Gurry, vice- diretor geral da OMPI, a anunciar que "novos centros de inovação, particularmente no nordeste da Ásia, estão surgindo e isso está transformando tanto a geografia do sistema de patentes como o futuro crescimento econômico global."

\section{Bilateralismo pós-TRIPS}

Diante do crescimento de registros de patentes internacionais pelos países em desenvolvimento, desde a formação da OMC e do fórum de resolução multilateral de disputas comerciais que ela administra, seria possível pensar que o bilateralismo, estratégia que os Estados Unidos usaram com êxito para pressionar os países em desenvolvimento, como o Brasil e a Índia, a concordarem com suas exigências sobre a propriedade intelectual antes do TRIPS, ${ }^{13}$ teria sido erradicado. Mas, em vez disso, não só o bilateralismo continuou a crescer como se expandiu continuamente. ${ }^{14}$ Desde 2000, os Estados Unidos concluíram os Acordos de Livre Comércio (FTAs ${ }^{15}$ ) bilaterais com Jordânia, Chile, Singapura, Austrália, Bahrein, Marrocos, El Salvador, Nicarágua, Honduras, Omã e Coréia. A União Européia também concluiu ou mostrou interesse em começar as negociações dos FTAs bilaterais com Asean ${ }^{16}$ [Associação das Nações do Sudeste Asiático], Guatemala, El Salvador, Honduras, Nicarágua, Costa Rica, Panamá, Índia, Coréia, Argentina, Brasil, Paraguai e Uruguai. A Austrália, o Canadá, o Japão e a Nova Zelândia fizeram seus próprios FTAs com outros países.

A pergunta óbvia é: por quê? E a resposta: em parte, porque fortalecer leis e mecanismos reguladores de propriedade intelectual favorece as indústrias farmacêuticas e de biotecnologia (CORREA, 2006). Como explica Carlos Correa:

\begin{abstract}
"Esses novos acordos de livre comércio, negociados fora da Organização Mundial do Comércio, requerem altos níveis de proteção à propriedade intelectual mais para os medicamentos do que aqueles decretados pelo Acordo TRIPS, e em alguns casos vão além do que é requerido nos países em desenvolvimento que os promovem." (CORREA, 2006)
\end{abstract}

Enquanto essa escalada da proteção à propriedade intelectual pode de alguma maneira explicar a busca contínua do bilateralismo em um mundo pós-TRIPS, pelos países desenvolvidos, especialmente por aqueles que têm indústrias farmacêuticas e biotecnológicas significativas, como os Estados Unidos e alguns da União Européia, isso não acontece com os países em desenvolvimento, especialmente quando, como aponta Correa, os mecanismos de proteção à propriedade intelectual mais forte requeridos por esses acordos bilaterais "reduz o acesso a medicamentos" (CORREA, 2006) e estão sujeitos à "opinião contrária de suas autoridades da saúde pública" (CORREA, 2006).

Trata-se de um paradoxo o fato de, apesar dessas desvantagens, o mundo em desenvolvimento estar aceitando a agenda bilateral dos países desenvolvidos, e as estatísticas da OMPI sobre patentes parecem confirmar isso. É claro que esse paradoxo tem uma explicação, pois o 
mundo em desenvolvimento não é irracional nem indiferente ao impacto que proteções mais fortes à propriedade intelectual impõem sobre a saúde de suas populações. Se alguém procurar uma resposta, pode parecer que ela se encontra em suas expectativas, estimulados pelos países desenvolvidos, de que a longo prazo a aquiescência às suas exigências sobre a propriedade intelectual vão acelerar a transformação de suas economias em desenvolvimento para desenvolvidas, atraindo investimento externo direto (IDE), e que sua transformação não só proporcionará padrões de vida mais altos, mas também estimulará o desenvolvimento industrial. Basicamente, eles aceitam que o sofrimento imediato imposto às suas populações, no que se refere à redução do acesso aos medicamentos, será transitória, uma vez que finalmente o IDE aumentará sua capacidade de produzir medicamentos por meio de suas próprias indústrias farmacêuticas e de biotecnologia. ${ }^{17}$

No entanto, enquanto isso soa possível, nem todos aceitam que o aumento do IDE será a panacéia econômica que o mundo em desenvolvimento espera (HALLWARD-DRIMEIER, 2003). Na verdade, há quem argumente que, embora o IDE possa muito bem aumentar, a qualidade desse investimento, juntamente com as restrições que lhe são impostas pelos acordos bilaterais, podem realmente atrasar ${ }^{18}$, mais do que contribuir para, seu desenvolvimento econômico.

Como indica Robert Wade,

"As regras que estão sendo redigidas nos acordos multilaterais e bilaterais definitivamente impedem que os países em desenvolvimento busquem os tipos de políticas industriais e tecnológicas adotadas pelos países do Leste Asiático que se desenvolveram recentemente e pelos que se desenvolveram anteriormente quando estavam em desenvolvimento." ${ }^{19}$ (WADE, 2003)

A disfunção descrita por Wade é visível quando se comparam as entradas de IED com as saídas de royalties ${ }^{20}$ (FINK et al., 2005) e outros custos, na forma de preços mais altos para mercadorias como medicamentos, ${ }^{21}$ causados pela aplicação de mecanismos de propriedade intelectual compatível com o TRIPS e com os acordos de livre comércio bilaterais pós-TRIPS. Enquanto uns argumentam que o aumento dos custos dos medicamentos nos países em desenvolvimento proporcionará benefícios positivos por estimular pesquisas para tratamentos de doenças endêmicas nesses países, tais como a malária e a tuberculose, outros indicam que isso não será um consolo para os pobres que não têm recursos para pagar o preço desses novos tratamentos e medicamentos. O que esse debate sugere é que o fortalecimento das leis de propriedade intelectual pelos países em desenvolvimento não resulta necessariamente em melhorar o acesso de sua população a tratamentos ou medicamentos baratos e que, como Ganlandt, Maskus e Wong, em nome do Banco Mundial, explicam: "esses problemas apontam diretamente para a necessidade de um maior interesse público em incentivar novas drogas e em adquirir e distribuir medicamentos" (FINK et al., 2005). Com isso, eles querem um esquema publicamente financiado, subsidiado por países desenvolvidos que conceda às empresas farmacêuticas uma "garantia de longo prazo para inovações" (FINK et al., 2005), de modo a estimulá-las ao desenvolvimento, à produção e ao fornecimento de medicamentos, para determinados países em desenvolvimento, a preços acessíveis "mas com rígidos controles para impedir que os medicamentos de baixo custo saiam daquelas áreas" (FINK et al., 2005). Se essa proposta é viável, não é algo que este artigo seja capaz de avaliar, mas o fato de ela ter sido proposta indica que os autores acreditam que, mesmo que o investimento externo direto realmente cresça nos países em desenvolvimento na mesma proporção que sua implementação de leis de propriedade intelectual mais fortes, não há a menor garantia de que isso leve as empresas farmacêuticas e biotecnológicas a se dedicarem à pesquisa e desenvolvimento que produzam os tratamentos e medicamentos necessários para reduzir as doenças e infecções no mundo em desenvolvimento. Em suas palavras, "o sistema predominante [de direitos de propriedade intelectual] não dá conta de oferecer incentivos suficientes para desenvolver novos tratamentos e distribuí-los a baixo custo" (FINK et al., 2005).

No entanto, além disso, o que o TRIPS e o bilateralismo pós-TRIPS impõe aos países em desenvolvimento, como Wade apontou, são regimes internacionais que efetivamente os priva de sua capacidade de adaptá-los a seus propósitos e implementam políticas concernentes ao reconhecimento e ao cumprimento da propriedade intelectual. É crítico, essas imposições não têm conseguido satisfazer o conjunto peculiar de circunstâncias econômicas que eles têm de enfocar, não só para alcançar as transformações econômicas que os tornariam um país desenvolvido, mas para alcançá-las de uma maneira que satisfaça também as necessidades sociais, éticas e morais de suas populações. O que é particularmente injusto, no que diz respeito tanto ao TRIPS quanto ao bilateralismo pós-TRIPS, é a não imposição de obrigações recíprocas ao países desenvolvidos, proprietários da grande maioria mundial da propriedade intelectual, para suprir os países em desenvolvimento de benefícios específicos, tangíveis e executáveis, de modo que eles possam confiar em seu caminho para se igualarem economicamente ao mundo desenvolvido. Precisamente, os benefícios aludidos nesse contexto vão além dos tipos de benefícios que fluiriam das reduções gerais de tarifas, taxas alfandegárias, cotas de importação para produtos agrícolas e subsídios para atividades agrícolas, como era o objetivo do GATT. Assim, parece que, em troca do GATT + TRIPS, o mundo desenvolvido não só estabeleceu um piso internacional para o reconhecimento mútuo e implementação da propriedade intelectual, como o fez sem que lhe fosse exigido estender o comércio tangível e os benefícios econômicos ao mundo em desenvolvimento além do que já era contemplado pelo GATT. Infelizmente, o bilateralismo pós-TRIPS somente agravou essa disparidade. A suposição que o mundo desenvolvido sempre fez, na busca do TRIPS e do bilateralismo pós-TRIPS é que, quanto mais fortes as proteções à propriedade intelectual dadas pelo mundo em desenvolvimento, maior a probabilidade de o investimento externo direto fluir proporcionalmente em sua direção. 
O problema dessa suposição, como explicou Mary Hallward-Driemeier, é que há uma ínfima evidência para sustentá-la (HALLWARD-DRIEMEIER, 2003). Ao contrário, a experiência chinesa mostra que fluxos de investimento externo direto não dependem do TRIPS nem dos acordos de livre comércio bilaterais pós-TRIPS. Antes mesmo de ter se tornado um membro da OMC em dezembro de 2001, a China recebeu fluxos significativos de IED e, em 2000, foi o país em desenvolvimento líder e o segundo (em relação aos Estados Unidos) entre os países da $\mathrm{APEC}^{22}$ (em matéria de seus fundos de IED de cerca de trezentos bilhões de dólares (GRAHAM et al., 2001). Esses fluxos de investimentos ocorreram embora a China tivesse uma má reputação relativa ao cumprimento dos direitos de propriedade intelectual antes de sua entrada para a OMC; mas, mesmo a partir do momento que entrou, de acordo com o Representante Comercial dos Estados Unidos (USTR), “destinando fracas proteção ao e implementação do IPR [direito de propriedade intelectual], a China continua a ser uma das principais prioridades da Administração" (USTR, 2005) e em seu 'Relatório Especial 301' explicou que os Estados Unidos eram “críticos [à China] no que se refere à falsificação desenfreada e aos problemas de pirataria que contaminam o mercado interno da China e ao fato de que a China se tornou a principal exportadora de mercadorias falsificadas e pirateadas para o mundo." (USTR, 2005). Como resultado, a China foi o assunto de uma avaliação separada feita pelo USTR que, em seu relatório, declarou:

"De modo geral, os índices de pirataria na China não declinaram de maneira significativa desde que se integrou à $\mathrm{OMC}$ e, em alguns setores, já cresceram para níveis extremamente altos. O relatório a ser submetido à avaliação em caráter extraordinário $\left(\mathrm{OCR}^{23}\right)$ avaliou perdas dos E.U., devido à pirataria de materiais com copyright, que variam de 2,5 bilhões de dólares a 3,8 bilhões por ano." (USTR, 2005)

Apesar das graves advertências e condenações do USTR, de acordo com o Ministério do Comércio da China, nos primeiros seis meses de 2004, os investimentos externos diretos aumentaram 12\%, chegando a 34 bilhões de dólares; em junho do mesmo ano, a General Motors confirmou que investiria três bilhões de dólares com o objetivo de dobrar sua capacidade de produção em 2007, e a Volkswagen AG anunciou que investiria quase um bilhão de dólares em duas fábricas de motores e uma de carros (CHINA DELAY, 2004).

Portanto, se a suposição de que maiores fluxos de investimento externo direto, que os países em desenvolvimento foram estimulados a esperar, em troca de se imporem e às suas populações exigências mais rigorosas de propriedade intelectual, é falsa ou exagerada, como então os países em desenvolvimento vão se transformar em desenvolvidos?

Uma opção é ignorar a falácia proposta dessa suposição e abraçar totalmente a agenda da propriedade intelectual estabelecida com o TRIPS e acelerada com o bilateralismo pós-TRIPS. Parece que as últimas estatísticas da OMC sobre os registros de patentes confirmam que isso é, de fato, o que fez o mundo em desenvolvimento. Certamente, um aumento de $27 \%$ nos registros de patentes internacionais, entre 2005 e 2006, dos sete principais (em matéria desse tipo de registro) países em desenvolvimento parece dar suporte à declaração da OMPI segundo a qual os regimes de propriedade intelectual pós-TRIPS estão de fato "transformando tanto a geografia do sistema de patentes como o futuro crescimento econômico global". Assim, se uma medida de desenvolvimento e de maior crescimento econômico é o número de pedidos de patentes internacionais registrado, há então algum espaço para o otimismo, e as estatísticas da China e da Coréia são positivas em relação a isso. No entanto, o problema é que se esses dois países ficarem do lado de fora da equação, emerge uma imagem bem diferente. Em vez de um crescimento de $27 \%$, há uma regressão de $6 \%$.

O crescimento econômico mundial dos países em desenvolvimento foi, portanto, afetado pelo Leste Asiático, que no caso da China pode ser atribuído em grau significativo aos níveis excepcionalmente altos do investimento externo direto que ela recebeu quando era a maior produtora mundial de mercadorias falsificadas e, no caso da Coréia, pode ser atribuído aos níveis de crescimento do investimento externo direto após 1997, à sua proximidade geográfica e econômica com a China, e à exportação de seus semicondutores para os Estados Unidos (MIN, 2006). O fato de nos últimos dez anos a economia chinesa ter crescido em níveis excepcionais assim como a demanda de semicondutores, por parte dos Estados Unidos, ter sido muito grande constitui uma explicação mais convincente para o crescimento econômico da Coréia e sua recuperação da crise econômica asiática de 1997 do que os regimes de propriedade intelectual pós-TRIPS.

Para que, então, o resto do mundo em desenvolvimento, os outros 104 países dos 136 assinaram o Tratado de Cooperação em Matéria de Patentes? Esta é uma questão importante e não pode ser mascarada pelo exagero sobre a contribuição que as fortes leis de propriedade intelectual dão ao seu desenvolvimento econômico, como é freqüentemente proclamado com efusividade pelas agências do mundo desenvolvido, tais como a OMPI, o Escritório Europeu de Patentes $\left(\mathrm{EPO}^{24}\right)$, o Escritório de Patentes e Marcas Registradas dos Estados Unidos $\left(\mathrm{USPTO}^{25}\right)$ e o Escritório Japonês de Patentes $\left(\mathrm{JPO}^{26}\right)$. Isso é verdade principalmente se aceitarmos que as opções de desenvolvimento econômico para o mundo em desenvolvimento foram restringidas, não fortalecidas, pelo TRIPS ${ }^{27}$ e pelo bilateralismo pós-TRIPS. ${ }^{28}$

\section{O debate sobre as patentes relacionadas aos recursos biológicos e ao conheci- mento tradicional: países desenvolvidos versus em desenvolvimento}

É interessante que, apesar das tentativas do Brasil, Paquistão, Peru, da Índia, Tailândia e Tanzânia de usarem o fórum multilateral da OMC para obterem reconhecimento internacional do papel que seus vastos recursos 
biológicos naturais e seu conhecimento tradicional desempenha, na pesquisa e desenvolvimento de novos tratamentos e medicamentos, não tenham tido o menor êxito. Seguindo seu caminho, a partir do exemplo dado tanto pelos Estados Unidos como pela União Européia desde antes de 1990, esses países em desenvolvimento tentaram, durante a Rodada de Doha da OMC, fazer uma emenda no TRIPS que proporcionaria que "quando o assunto envolver o pedido de uma patente derivada de, ou desenvolvida com recursos biológicos e/ou associada ao conhecimento tradicional, os membros devem requerer aos solicitantes que revelem o país que fornece os recursos e/ou o conhecimento tradicional associado ...". ${ }^{29} \mathrm{~A}$ diferença entre as duas situações é que, ao contrário dos Estados Unidos e da União Européia, que tiveram o apoio do mundo desenvolvido em 1990, o Brasil, Paquistão, Peru, a Índia, Tailândia e Tanzânia não o tiveram em 2006. Em um caso clássico de uma lei para os desenvolvidos e outra para os países em desenvolvimento, os desenvolvidos tumultuaram o debate na OMC e tentaram quebrar a determinação dos países em desenvolvimento, usando o bilateralismo como alavanca. ${ }^{30}$

No entanto, os EU, a UE, o Japão e a maioria do mundo desenvolvido não expressou oposição direta à idéia, mas ao processo de chegar a um consenso. Sua posição foi firme; primeiro precisava haver princípios e objetivos estabelecidos que levassem a definições precisas de propriedade dos recursos biológicos e do conhecimento tradicional (NEW, 2006). Obviamente, há mais em relação ao argumento do que isso. A causa essencial do desentendimento entre o Norte e o Sul a respeito da questão dos recursos biológicos e do conhecimento tradicional é se o sistema de patentes é o veículo apropriado para levar à frente a discussão. Os países em desenvolvimento estão confiantes no sistema de patentes no qual baseiam sua reivindicação de proteção da propriedade intelectual para esses recursos. Por outro lado, os países desenvolvidos acreditam que "requerimentos para revelação de novas patentes não são uma solução apropriada para satisfazer as preocupações levantadas" (WTO, 2006) e que no que diz respeito à apropriação desses recursos "uma solução mais adequada ... seria fortalecer os regimes nacionais fora dos sistemas de patentes" (WTO, 2006). De acordo com o mundo desenvolvido, deixando o sistema de patentes intato, ao mesmo tempo o mundo em desenvolvimento deveria usar controles de leis ad hoc e de regulação fragmentados para fortalecer o acesso à exploração de seus vastos recursos biológicos. A idéia é que, através desses controles, o mundo em desenvolvimento ficará melhor capacitado para negociar os termos em que as indústrias farmacêuticas e biotecnológicas do mundo desenvolvido poderão explorar as florestas tropicais enquanto buscam identificar materiais biológicos úteis farmacologicamente, mas encontrados na natureza.

A preocupação básica dos países desenvolvidos é o impacto que a modificação do sistema de patentes teria sobre suas empresas farmacêuticas e biotecnológicas, muitas das quais obtêm patentes nos compostos derivados de materiais biológicos encontrados na natureza. Em nenhum outro lugar essa preocupação é mais evidente do que nos Estados Unidos, que publicam patentes sobre materiais biológicos isolados que, por outro lado, são idênticos aos materiais biológicos encontrados na natureza. As questões sobre o que é a 'invenção' e o que levou à 'invenção', na jurisprudência convencional sobre patentes norte-americana, não se estendem àqueles que indicaram o caminho, e para os EU, não há nenhum bom motivo comercial para acreditar naquele caminho. Na verdade, a idéia de dividir uma parte dos bilhões de dólares equivalentes à renda gerada por medicamentos desenvolvidos a partir de recursos biológicos naturais com o país de origem daquele material, ou com os donos do conhecimento tradicional que levou à descoberta das substâncias farmacológicas, é um anátema.

Os Estados Unidos sustentam veementemente que o trabalho que leva à 'invenção' com o objetivo de obter uma patente não pode incluir o simples fato de que os materiais biológicos dos quais o composto relevante foi isolado ou derivou teve origem em um país em desenvolvimento ou se tornou possível graças ao conhecimento tradicional de nativos do local (WTO, 2006). Compatível com a jurisprudência norte-americana sobre patentes, há uma diferença significativa entre o composto natural in situ e a 'invenção' de um medicamento ou tratamento derivado daquele composto, e os Estados Unidos explicaram que essa distinção "visualiza os esforços dispendiosos reais e freqüentes empreendidos para transformar um recurso biológico em um produto bem-sucedido comercialmente, e os riscos envolvidos na realização de uma pesquisa e desenvolvimento como essa" (WTO, 2006).

\section{A resolução do impasse relativo ao patenteamento}

Os países desenvolvidos e os em desenvolvimento estão diante de um impasse. ${ }^{31} \mathrm{~A}$ menos que este seja resolvido, a OMC, como fórum, terá decepcionado o mundo em desenvolvimento que, por um lado, aceitou as demandas dos países desenvolvidos de proteções mais severas à propriedade intelectual e, por outro, está buscando a cooperação dos países desenvolvidos com o objetivo de usar exatamente as mesmas proteções de propriedade intelectual para explorar legitimamente seus valiosos e vastos recursos biológicos e de conhecimento tradicional. O problema é que enquanto os dois lados estão certos, também estão errados! Do ponto de vista de se chegar a uma proposta alternativa que seja mutuamente aceitável, as hipóteses de que ambos façam algo para resolver o problema do sistema de patentes e de sua aceitabilidade, oferecendo proteções à propriedade intelectual dos materiais biológicos farmacologicamente úteis encontrados na natureza, precisam ser testadas. Na verdade, enquanto o mundo desenvolvido está certo de apontar que é necessária uma pesquisa significativa para transformar um material biológico encontrado na natureza em um tratamento ou medicamento eficazes, freqüentemente o ponto de partida dessa pesquisa não é algo 'inventado', mas sobretudo simplesmente um derivado isolado do material biológico encontrado na 
natureza. O mundo desenvolvido usa essa distinção como uma espada contra o mundo em desenvolvimento.

O ponto de partida para esse exercício remonta a 1988, quando foram levantadas questões sobre a patenteabilidade de materiais biológicos isolados como produtos. Naquela época, o USPTO, EPO e JPO publicaram conjuntamente um comunicado que determinava em termos absolutos que materiais biológicos isolados não são excluídos da patenteabilidade porque não são produtos da natureza, mas 'invenções'. ${ }^{32}$ Finalmente, em 2000, os Estados Unidos aprovaram a Diretriz de Biotecnologia para esclarecer essa questão de acordo com a lei de patentes européia ${ }^{33}$ e, obviamente, no início de 1980, foi atribuída ao caso de Diamond v Chakrabarty ${ }^{34}$ na Suprema Corte norte-americana a carta branca dada à indústria biotecnológica para patentear qualquer coisa feita pelo homem, inclusive organismos vivos geneticamente modificados.

Entretanto, a proposta básica de que materiais biológicos são patenteáveis não tinha sido adequadamente respondida e há um preocupação muito real se são de fato 'invenções' ${ }^{35}$ Nesse sentido, é preciso observar que, no caso da Kirin-Amgen, Inc v Hoechst Marion Roussel Ltd, a Câmara dos Lordes inglesa sustentou que as demandas de patentes para o hormônio humano eritropoietina, mesmo numa forma isolada e produzida por meios técnicos, não eram válidas porque o hormônio, mesmo em uma forma isolada e purificada, não era novo. Mais recentemente, a Suprema Corte americana questionou exatamente como uma lei de patentes remota pode invadir legitimamente as áreas do que deveria ser de domínio público. No caso do Laboratory Corporation v Metabolite Laboratories, ${ }^{36}$ o magistrado Breyer explicou que o princípio da lei que exclui fenômenos naturais da patenteabilidade "encontra suas raízes tanto na lei inglesa como na americana” e que "a razão para a exclusão é que, às vezes, muitas proteções a patentes podem impedir mais do que 'estimular o progresso da ciência' ... [aspas dele] porque as patentes "podem desestimular a pesquisa por impedirem a livre troca de informações, por exemplo, obrigando os pesquisadores a evitar o uso de idéias possivelmente patenteadas, levando-os a conduzir pesquisas caras e que consomem muito tempo de patentes existentes ou pendentes, exigindo preparações para licenciamento complexas, e aumentando os custos para o uso de informações patenteadas, às vezes de forma proibitiva".

O xis do problema da lei de patentes é o simples fato de que muito do valor comercial da propriedade intelectual reside na produção dos materiais biológicos isolados, que simplesmente duplicam a função ou o desempenho daqueles encontrados na natureza. A identidade do in vivo é que é valiosa, mas é isso que afeta a proibição do patenteamento de "leis da natureza, fenômenos físicos, e idéias abstratas" ${ }^{37}$ que está implícita na lei de patentes. No entanto, esse aspecto não foi aceito pelas indústrias farmacêuticas e biotecnológicas, particularmente nos Estados Unidos, na União Européia e no Japão. Ou melhor, por interesse comercial e com o objetivo de manter suas patentes protegidas, elas cuidadosamente evitaram levan- tar essa questão diante das cortes. Conseqüentemente, para elas, o Santo Graal está em garantir a proteção das patentes dos produtos isolados derivados dos materiais biológicos naturais. Obviamente, o mundo em desenvolvimento quer uma fatia da realização.

O problema, como explicou Stephen Crespi, é que “a palavra 'inventado' soa artificial quando aplicada a algo já existente” (CRESPI, 1995). É claro que ele está certo porque é impossível inventar algo que já existe, mesmo que sua existência não seja conhecida. Para sugerir, como ele faz, que "a palavra 'descoberta' ... subestima o trabalho meticuloso que deve ser feito pelo cientista antes de conseguir ver a substância pura no tubo de ensaio" (CRESPI, 1995), e que, portanto, o 'isolamento’ é um mecanismo legítimo para transformar um produto da natureza (isto é, uma 'descoberta') em um produto do homem (isto é, algo capaz de ser uma 'invenção'), ignora o fato de que o limiar para a 'invenção', no sistema de patentes, não é o “trabalho meticuloso”, mas a própria 'invenção'. Se não fosse assim, então literalmente qualquer coisa "feita pelo homem” poderia ser considerada uma 'invenção’ e isso, como a Suprema Corte deixou totalmente claro no caso Diamond versus Chakrabarty, não é suficiente. Admitindo a intenção do Congresso, por muitos compartilhada, de aprovar o patenteamento de uma série de tecnologias, adotando as palavras "qualquer coisa feita pelo homem", a Suprema Corte norte-americana não quis dizer que o trabalho trivial rotineiro ou mesmo o meticuloso daria ao homem o direito de reivindicar, como seu, um organismo vivo. Ou melhor, é necessário que o trabalho que leva à sua criação não só seja substancial ${ }^{38}$, mas que o próprio organismo revele características não encontradas na natureza. ${ }^{39}$

Como freqüentemente acontece, a maioria das patentes sobre materiais biológicos isolados demanda o direito de propriedade de materiais biológicos substancialmente idênticos aos encontrados na natureza, que são geneticamente e biologicamente semelhantes, além de terem a mesma eficácia e, queira ou não queira, o 'trabalho meticuloso' envolvido em sua identificação e isolamento não os torna aptos à proteção da patente. Infelizmente, isso não dá atenção ao fato de que a capacidade de produzir em massa materiais biológicos isolados é comercialmente, medicamente e cientificamente vantajosa, que o isolamento dos materiais biológicos contribuiu amplamente para a melhora da saúde humana no mundo inteiro e que esse trabalho é meticuloso, caro, arriscado e consome tempo.

Nessas circunstâncias, não só é justo, mas também apropriado, que o trabalho que facilitou o isolamento de materiais biológicos, incluindo sua identificação, seja recompensado? Essa é a pergunta que Stephen Crespi, as indústrias farmacêuticas e biotecnológicas e o mundo desenvolvido fizeram inúmeras vezes. No entanto, seu problema tem sido obstinadamente contar com o sistema de patentes, mais do que defender um direito sui generis de propriedade intelectual. $\mathrm{O}$ que eles não aceitaram é que o sistema de patentes tem seus limites - que o mapa da estrada está ultrapassado. Infelizmente, ao se juntar à caravana do mundo desenvolvido, os países em 
desenvolvimento estão fazendo a mesma viagem usando o mesmo ultrapassado mapa da estrada, tendo de suportar durante todo o tempo as tentativas do mundo desenvolvido de se afastar da diligência do mundo em desenvolvimento. A ironia é que, ao mesmo tempo que eles duelam e discutem, estão na mesma estrada que está prestes a ser excluída do mapa.

Se tanto o mundo desenvolvido quanto o em desenvolvimento acreditam que é conveniente estimular a pesquisa de novos tratamentos e medicamentos e que, muito provavelmente, estes serão extraídos dos vastos e variados recursos biológicos das florestas tropicais do mundo em desenvolvimento, não é a solução a ser encontrada na criação de um sistema de propriedade intelectual sui generis que torna possível atingir esse objetivo? Este artigo sustenta que sim e propõe a criação do Direito da Seqüência Genética (GSR) como um sistema sui generis de propriedade intelectual.

\section{O direito da seqüência genética: um sistema sui generis de propriedade intelectual}

De acordo com essa proposta, o GSR seria gerenciado usando o sistema administrativo existente utilizado pelo sistema de patentes 'internacional' de modo a minimizar os custos de instituí-lo e a facilitar sua adoção. Um GSR seria concedido para a primeira pessoa a registrar e revelar uma seqüência genética definindo um material biológico de qualquer origem e explicando sua função e utilidade. Um GSR deveria estar sujeito a um pedido escrito registrado no escritório de patentes do país em que for pedido, de maneira semelhante a um pedido de uma patente para o PCT. O GSR deveria se tornar parte de um banco de dados eletrônico internacional ao qual qualquer pessoa teria livre acesso.

É importante que, se a seqüência genética tiver sido identificada por intermédio do fornecimento de conhecimento ou informações tradicionais, tribais ou locais, uma parte da remuneração devida para o detentor do GSR seria paga às pessoas que são donas daquele conhecimento ou informações. O direito delas seria proporcional à contribuição dada na identificação da seqüência genética e seria determinado pela autoridade central administrativa, que também fiscalizaria a distribuição da receita da remuneração do GSR para os respectivos países e populações locais. Isso certamente proporcionaria benefícios econômicos não só para os países em desenvolvimento, mas também para seus povos nativos.

Uma vez registrado, o detentor do GSR teria o direito a uma remuneração pelo uso do GSR (remuneração do GSR). A remuneração do GSR variaria conforme a natureza do uso. Para instituições públicas, tais como universidades, o uso experimental não estaria sujeito a uma remuneração do GSR, mas para entidades comerciais, a remuneração do GSR seria cobrada proporcionalmente à natureza do uso. Por exemplo, poderia haver uma escala para entidades comerciais tendo como piso o uso experimental que avançaria até a comercialização completa. Imagina-se que haveria um grande número de variações entre esses extremos. A quantia da remuneração de GSR seria estabelecida por uma escala de domínio público, determinada por um órgão mundial centralizado responsável pela administração global do GSR, por exemplo, a OMPI. O referido órgão recolheria e distribuiria a receita da remuneração do GSR e poderia receber rendimentos pelo recolhimento do pedido e remunerações de administração anuais, assim como deter uma pequena porcentagem da receita da remuneração do GSR coletada. Concessões específicas poderiam também ser feitas aos detentores do GSR que solicitassem remunerações do GSR acima da escala de domínio público, se conseguissem estabelecer que, devido a fatores relacionados à natureza do GSR ou a acontecimentos imprevistos (por exemplo, guerra), o montante das remunerações do GSR seriam insuficientes para recuperar, de maneira satisfatória, o investimento na pesquisa e desenvolvimento que levaram ao GSR.

Aos usuários do GSR seria exigido registrar seu uso com a autoridade administrativa local e esse uso seria registrado no banco de dados eletrônico do GSR. Isso proporcionaria um registro público do uso.

A vida do GSR seria de dez anos a partir da data de registro. Violação dos GSRs poderia ser tratada pelos tribunais nacionais pertinentes. Conseqüentemente, o detentor teria o direito de tentar injunções, declarações ou indenizações. Disposições criminais também a considerariam um crime de violação dos direitos do detentor do GSR.

Portanto, o GSR propiciaria um sistema pelo qual os países em desenvolvimento, que são a fonte dos materiais biológicos, assim como investidores em pesquisa genética poderiam ser remunerados sem que os detentores do GSR tenham o poder de controlar que uso pode ser feito daquele GSR. Assim, o GSR facilitaria a publicação de informações sobre seqüências genéticas e estimularia o uso de informações de seqüências genéticas, a produção de materiais biológicos correspondentes e seu uso no desenvolvimento de novos tratamentos e medicamentos. No entanto, removendo o elemento de controle absoluto, o GSR evitaria que os detentores de GSR controlassem outras pesquisas down-stream ${ }^{40}$ ou outros usos. ${ }^{41}$ Este é um aspecto importante do GSR para os países em desenvolvimento e seu acesso a medicamentos baratos, porque ao mesmo tempo que receberiam rendimentos pela exploração de seus recursos biológicos por parte do mundo desenvolvido, poderiam usar os próprios materiais biológicos para realizar pesquisa e desenvolvimento de modo a desenvolver e produzir seus próprios tratamentos e medicamentos. Assim, eles não precisariam depender das indústrias farmacêuticas e biotecnológicas do mundo desenvolvido, e poderiam desenvolver as suas próprias. Esta é uma vantagem significativa sobre o atual sistema de patentes que os impede dessa capacidade por conferir o controle absoluto do material biológico isolado aos proprietários de patentes que, em sua maioria, são do mundo desenvolvido.

O detentor do GSR não precisaria satisfazer qualquer critério de 'invenção' ou de 'passo inventivo'. A novidade da seqüência genética poderia ser estabelecida por uma 
pesquisa no banco de dados de GSRs ou em outros bancos de dados de seqüências genéticas. Poderia ser estabelecida também pela função e utilidade, de modo que mesmo se a seqüência genética já fosse conhecida ou fosse assunto de um GSR existente, se estabelecida uma diferente função e utilidade desconhecida anteriormente, poderia dar origem a um novo GSR. No entanto, uma ampla descrição do GSR relativa à função e utilidade não seria permitida, a menos que comprovada do início ao fim da descrição. Conseqüentemente, o GSR incorporaria uma descrição da função e utilidade da seqüência genética.

O GSR abordaria também as diversas preocupações que rodeiam o uso experimental. Uma questão problemática com as isenções para uso experimental para violações de patentes no contexto da biotecnologia, é que foram concedidas muitas patentes sobre 'instrumentos de pesquisa' que são úteis na pesquisa de novos medicamentos. No contexto de cada um desses pedidos, os materiais biológicos patenteados foram usados por instituições de pesquisas, como universidades, e a questão levantada é se esse uso é ou deveria ser isentado da violação de patentes.

Com o GSR, o uso por uma instituição de ensino ou pesquisa teria custo zero de acordo com as determinações da remuneração do GSR. No entanto, o uso de um GSR por uma entidade comercial, seja direta ou indiretamente por meio de uma universidade, envolveria uma remuneração do GSR proporcional a esse uso. A obrigação de pagar a remuneração do GSR permaneceria com a entidade comercial. Portanto, se qualquer entidade comercial fizesse um acordo com uma universidade para conduzir uma pesquisa em nome dela ou como parte de um empreendimento conjunto ou colaboração, a obrigação de pagar a remuneração do GSR continuaria. Isso acabaria com a discussão sobre quando, e se, universidades que realizam pesquisas financiadas comercialmente devem ficar isentas no caso de uso experimental. ${ }^{42}$

A proposta do GSR reconhece que o uso de seqüências genéticas ou de materiais biológicos (idênticos às seqüências e materiais encontrados na natureza), qualquer que seja o objetivo, não deve ser controlado nem ficar sob a propriedade e o controle de qualquer organização ou indivíduo. Sua proposta é estimular o uso por terceiros. Ela reconhece que independente de uma seqüência genética ser uma 'invenção' ou não, a elucidação de uma seqüência genética e a identificação de sua função é um trabalho importante que deve ser incentivado. Portanto, permite que universidades recebam financiamentos para seus projetos de pesquisa tornando-se detentoras do GSR sem qualquer obrigação de pagar remunerações do GSR. Propicia um sistema para registrar GSRs e ter acesso a que usos eles se aplicam. O fato de que as universidades estejam na área de negócios relativos à educação ou que, hoje, se vejam como parte de um mundo comercial mais amplo torna-se irrelevante.

Ao contrário do sistema de patentes, que cria propriedade na invenção patenteada e dá ao proprietário da patente o direito de negociar aquela propriedade como ele ou ela considerar apropriado, o GSR não o faz. Ou melhor, o detentor do GSR é reconhecido como o primeiro a auto- rizar a publicação sobre novos materiais biológicos e sua função e, de acordo com o quid pro quo por sua divulgação, tem o direito de receber uma receita da remuneração do GSR. Conseqüentemente, quanto mais uso tiver aquele GSR, maior a receita potencial da remuneração do GSR; ao passo que, com o sistema de patentes, o preço da invenção patenteada pode estar sujeito à manipulação por meio da capacidade do patenteador de controlar o uso por terceiros. É essa capacidade de controlar e restringir o uso que justifica a isenção no caso de uso experimental numa tentativa de equilibrar as necessidades do patenteador e as da sociedade. No entanto, com o GSR, nenhum equilíbrio adicional ou sintonia fina são requeridos, porque todo o sistema se destina a estimular igualmente o uso comercial e não-comercial.

\section{Conclusão}

O GATT, produto das negociações de Bretton Woods, em 1944, foi o ápice do trabalho de Cordell Hull. ${ }^{43}$ Hull acreditava que "a liberdade no comércio está intimamente ligada à paz” (HULL, 1981), e desde que ele escreveu essas palavras, em 1948, contribuiu para grande parte da retórica sobre o livre comércio que se espalhou por intermédio do USTR. No entanto, para o mundo em desenvolvimento que, desde a Segunda Guerra Mundial, busca independência, desenvolvimento e uma parte legítima da riqueza do mundo desenvolvido para si e suas populações, certamente elas devem soar vazias. Hull responsabilizou o bilateralismo e as "altas tarifas, barreira comerciais e concorrência econômica injusta" (HULL, 1981), por ele produzidas, por muitos dos problemas econômicos mundiais.

Este texto argumentou que a OMC, filha do GATT + TRIPS, fez pouco para preencher a lacuna entre o mundo desenvolvido e o em desenvolvimento mas, em alguma medida, propiciou uma distorção menor dos objetivos do GATT ao incorporar a propriedade intelectual à equação do livre comércio mundial. Com isso, e com o apoio do mundo em desenvolvimento, o mundo desenvolvido abandonou o fórum multilateral em favor do bilateralismo. Ao fazer isso, foi motivado por suas necessidades a proteger a propriedade intelectual, mais do que o TRIPS já havia feito.

Atualmente, os países em desenvolvimento buscam criar suas próprias formas de propriedade intelectual, baseadas no valor de seus próprios recursos biológicos e no conhecimento tradicional acumulado de suas populações. Não só é justo que o mundo desenvolvido os ajude nessa ambição, mas essencial que faça com que isso aconteça de modo que "os padrões de vida de todos os países possam crescer” (HULL, 1981).

A proposta do GSR é simplesmente uma tentativa de resolver uma das questões que criou um impasse para os países desenvolvidos e os em desenvolvimento durante a Rodada de Doha da OMC e espera-se que ele possa levar a alguma discussão frutífera.

\section{Notas}

1. Trade-Related Aspects of Intellectual Property Rights. (N.T.) 
2. General Agreement on Tariffs and Trade [Acordo Geral de Tarifas e Comércio]. (N.T.)

3. Lista de assuntos para negociações no texto da reunião ministerial do Gatt datado de 20 de setembro de 1986.

4. A questão da falsificação de mercadorias com marca registrada surgiu primeiro durante a Rodada Tóquio do GATT entre 1973 e 1979. Isso levou à circulação de um esboço para Agreement on Measures to Discourage the Importation of Counterfeit Goods [Acordo sobre medidas para desestimular a importação de mercadorias falsificadas] entre 1979 e 1984. Por sua vez, esse esboço levou à formação de The Group of Experts on Trade in Counterfeit Goods [Grupo de especialistas em comércio de mercadorias falsificadas] que se reuniu em setembro e outubro de 1985. Na verdade, mesmo no início da Rodada Uruguai, em setembro de 1986, o foco permaneceu nas mercadorias falsificadas como sugere o nome do grupo de negociações presidido pelo embaixador da Suécia, Lars Anell. Ele foi denominado Negotiating Group on Trade-Related Aspects of Intellectual Property Rights, Including Trade in Counterfeit Goods [Grupo de negociações sobre aspectos dos direitos de propriedade intelectual relacionados ao comércio, incluindo o comércio de mercadorias falsificadas].

5. O esboço dos Estados Unidos do Acordo sobre os aspectos dos direitos de propriedade intelectual relacionados ao comércio foi proposto em maio de 1990.

6 Gervais explica que “esta estrutura 'comum' foi finalmente adotada e, submetida a poucas mudanças, serviu como base para o Tratado que emergiu”. Ibid.

7. Alemanha, Austrália, Áustria, Bélgica, Canadá, Coréia, Dinamarca, Eslováquia, Espanha, Estados Unidos, França, Grécia, Hong Kong, Hungria, Islândia, Irlanda, Itália, Japão, Luxemburgo, Malásia, Malta, Holanda, Nova Zelândia, Noruega, Portugal, Reino Unido, República Checa, República da Macedônia, Romênia, Singapura e Suécia. A Comunidade Européia é um membro separado.

8. África do Sul, Argentina, Bahrein, Bangladesh, Barbados, Belize, Brasil, Brunei, Chile, Costa Rica,

Costa do Marfim, Dominica, Filipinas, Gabão, Gana, Grenada, Guiana, Honduras, Índia, Indonésia, Kuwait, Macau, Maurício, México, Marrocos, Mianmá, Nigéria, Paquistão, Paraguai, Peru, Quênia, Santa Lúcia, São Vincente \& Granadinas, Senegal, Sri Lanka, Suriname, Suazilândia, Tanzânia, Tailândia, Uganda, Uruguai, Venezuela e Zâmbia.

${ }^{9}$ De 77 membros em $1^{\circ}$ de janeiro de 1995 para 150 membros em 11 de janeiro de 2007.

10 WIPO, na sigla em inglês para World Intellectual Property Organization. (N.T.)

${ }^{11}$ Patent Cooperation Treaty. Cabe observar que o Instituto Nacional da Propriedade Intelectual, no Brasil, traduz o nome do tratado, mas conserva sua sigla em inglês. Quando o mesmo acontecer com outros tratados, associações, acordos etc., nesta ou em outra instituição governamental brasileira, a sigla aparecerá entre parênteses sem qualquer observação (N.T.)

12. Ibid. Esses países incluem a Coréia (5.935 pedidos ao PCT); China (3.910); Índia (627); Singapura (402), África do Sul (349); Brasil (265) e México (150).

13. "Cada acordo bilateral aproximava muito mais aquele país do TRIPS, de modo que aceitá-lo não era nada extraordinário". Um negociador comercial norteamericano citado por P. Drahos, op. cit., nota de rodapé 11, p. 105.

14. "Durante 2006, mais de 100 países em desenvolvimento se engajaram em mais de 67 negociações comerciais bilaterais ou regionais, e assinaram mais de 60 tratados bilaterais de investimentos. Mais de 250 acordos comerciais regionais e bilaterais agora regulam mais de 30\% do comércio mundial, enquanto uma média de dois tratados bilaterais de investimento por ano foram realizados nos últimos dez anos." Oxfam Briefing Paper, Signing Away The Future, março de 2007, p. 5.

15. Free Trade Agreements. (N.T.)

16. Association of the SouthEast Asian Nations. (N.T.)

17. "Isto se dá, em certa medida, porque muitas atividades de pesquisa e desenvolvimento em que as empresas indianas participam são pequenas modificações de produtos farmacêuticos desenvolvidos no exterior (principalmente ocidentais), e porque muito pouco esforço tem sido feito para o desenvolvimento de qualquer novo medicamento. No entanto, provavelmente essa situação vai mudar logo, com o surgimento de grandes empresas de pesquisa e desenvolvimento indianas, tais como os laboratórios Ranbaxy e o Dr. Reddy". Shamnad Basheer, Limiting The Patentability of Pharmaceuticals Inventions and Micro-Organisms: a TRIPS Compatibility Review, novembro de 2005.

18. "O TRIPS aumenta o preço do conhecimento patenteável para os consumidores e, assim, aumenta o fluxo de renda do Sul para o Norte. De acordo com estimativas do Banco Mundial, as empresas norte-americanas devem embolsar um adicional líquido de 19 bilhões por ano em royalties a partir da plena aplicação do TRIPS. Elas possuem muitas patentes em muitos países solicitados a estreitar a proteção à propriedade intelectual, enquanto o TRIPS não requer estreitamento da lei de patentes norte-americana." Robert H. Wade. What Strategies Are Viable For Developing Countries Today? The WTO and the Shrinking of 'Development Space', Review of International Political Economy, 10:4, novembro de 2003: p. 621 -644, p. 624.

19. Ibid., p. 622. Para uma história excelente e detalhada de como os Estados Unidos estabeleceram suas indústrias químicas e farmacêuticas. Em 1919, confiscando 5 mil patentes da Alemanha, ver Kathryn Steen, Patents, Patriotism, and "Skilled in the Art", The History of Science Society, 2001, 92:91-121.

20. Carsten Fink and Keith Maskus (Ed). Intellectual Pro- 
perty And Development, World Bank and Oxford University Press, 2005, particularmente Keith Maskus, Capítulo 3, p. 41-73, na p. 44 Quadro 3.1, e na p. 46 Quadro 3.2.

21. "Em termos econômicos, de acordo com o sistema atual, os incentivos para atingir uma dinâmica eficiente e uma provisão fixa de medicamentos são extremamente inadequados diante da pobreza maciça. Dois programas foram desenvolvidos nos últimos anos para tentar resolver o problema; esses programas estão consideravelmente em conflito um com o outro. Por um lado, o Acordo sobre Aspectos dos Direitos de Propriedade Intelectual relacionados ao Comércio (TRIPS) dentro da Organização Mundial do Comércio (OMC) requer que os países membros concedam e implementem patentes para novos produtos farmacêuticos (Maskus, 2000a; Gorlin 1999). Mais precisamente, produtores de novos medicamentos desfrutaram dos direitos exclusivos de comercialização (EMRs) a todos os membros da OMC desde janeiro de 1995. Embora, até 2005, não se requeressem patentes dos produtos nos menores países desenvolvidos, os EMRs oferecem proteção similar. Vários estudos econômicos sugerem que esse novo regime poderia aumentar os preços dos novos medicamentos de maneira notável nos países em desenvolvimento (Fink, 2000; Lanjouw, 1998; Subramanian, 1995; Watal, 1999); no entanto, continua a existir uma incerteza substancial sobre essa questão. Assim, há alguma possibilidade de que patentes aumentem os incentivos para a pesquisa e o desenvolvimento relacionados a essas doenças negligenciadas (Lanjouw, 1998). Entretanto, essa mudança política nada faz diretamente para aumentar os rendimentos de pacientes que, se nada mudar, devem passar a ter menos condições de comprar novos medicamentos." Ibid., Mattias Ganslandt, Keith Maskus and Eina Wong, capítulo 9, p. 207-223 na p. 208.

22. Asia-Pacific Economic Cooperation [Cooperação Econômica da Ásia e do Pacífico]. (N.T.)

23. Out-of-cycle review. (N.T.)

\section{European Patent Office. (N.T.)}

25. United States Patent and Trademark Office. (N.T.)

\section{Japanese Patent Office. (N.T.)}

27. Por exemplo, o art. 30 do TRIPS restringe a possibilidade de membros da OMC implementarem políticas que restrinjam os "direitos exclusivos conferidos por uma patente”. É bem documentado que, nas legislações de patentes que vigoraram em muitos países da Europa até cerca de 1980, patentes de produtos farmacêuticos e químicos não eram permitidas (a Itália é um exemplo). Além disso, entre 1907 e 1977, a legislação de patentes do Reino Unido dispôs especificamente contra uma patente de medicamentos que ali não deveria funcionar. Disposições semelhantes existiram nas leis de patentes da maioria dos países europeus, inclusive França e Alemanha. Essas restrições à propriedade intelectual estavam de acordo com políticas econômicas específicas destinadas a favorecer o desenvolvimento econômico em diversos países.
28. "O pior acordo priva os países em desenvolvimento da capacidade de governar efetivamente suas economias e proteger suas populações mais pobres. Além das disposições negociadas num nível multilateral, ele impõe regras devastadoras, difíceis de reverter, que sistematicamente desmantelam políticas nacionais destinadas a promover o desenvolvimento." Oxfam Briefing Paper, Signing Away The Future, março de 2007, p. 2.

29. Communication from Brazil, India, Pakistan, Peru, Thailand and Tanzania to the General Council, Trade Negotiations Committee, WTO, WT/GC/W/564, 31 de maio de 2006, p. 2. Artigo sugerido 29 bis, intitulado "Disclosure of Origin of Biological Resources and/or Associated Traditional Knowledge".

30. Em uma carta lateral assinada em abril de 2006 para o Acordo de Livre Comércio entre Estados Unidos e Peru foi combinado que "As partes reconhecem a importância do conhecimento tradicional e da biodiversidade, assim como a possível contribuição do conhecimento tradicional e da biodiversidade para o desenvolvimento cultural, econômico e social".

31. No dia 4 de abril de 1007, o Comissário de Comércio dos Estados Unidos, Peter Mandelson, na véspera das discussões ministeriais a serem realizadas em Nova Délhi, disse que "essas conversas são oportunas e importantes [e que] se não tivermos êxito, as perspectivas de Doha para este ano serão perdidas".

32. "Produtos naturais purificados não são considerados em qualquer dessas três leis como produtos da natureza ou dscobertas porque de fato eles não existem na natureza numa forma isolada. Ou melhor, eles são considerados, para os propósitos de patentes, como substências biologicamente ativas ou compostos químicos e aceitáveis para patenteamento na mesma base que outros compostos químicos." A fonte desse texto encontra-se na nota de rodapé 9, Nuffield Council of Bioethics Discussion Paper, 2002, The Ethics of Patenting DNA, 26, para 3.14.

33. Artigo 3.2. “O material biológico que é isolado de seu ambiente natural ou produzido por meio de um processo técnico pode constituir uma invenção patenteável, mesmo que isso ocorresse previamente na natureza."

34. Diamond, the Commissioner of Patents v Chakrabarty (1980) 447 U.S. 303 (Suprema Corte norte-americana).

35. Para uma explicação detalhada do argumento na jurisprudência, ver Luigi Palombi. The Patenting of Biological Materials In The Context of TRIPS. PhD Thesis, University of New South Wales, Sydney, Australia, setembro de 2004.<http://cgkd.anu.edu.au/menus/PDFs/ PhDThesisFinal.pdf. $>$

36. Laboratory Corporation v Metabolite Laboratories (2006) 126 S. Ct. 2921 at 2922-3.

37. Op. cit. 55, p. 309.

38. Neste caso, o trabalho foi a manipulação da bactéria natural e não simplesmente seu isolamento. 
39. “... o patenteador produziu uma nova bactéria com características consideravelmente diferentes de qualquer uma encontrada na natureza e que tem o potencial para uma utilidade significativa." Diamond, The Commissioner of Patents v Chakrabarty (1980) 447 U.S. 303 (Suprema Corte norte-americana) per Justice Berger, p. 305.

40. No contexto da genética, a palavra down-stream está relacionada ao processo de formação do ácido rinobucléico (ARN) a partir do ácido desoxirribonucléico (ADN ou, em inglês, DNA), à especificação da seqüência de aminoácidos pelo mensageiro ARN para a síntese de uma proteína. No que se refere à produção de medicamentos, a pesquisa down-stream tem sido amplamente utilizada na síntese ou elaboração de substâncias complexas como hormônios (por exemplo, a insulina), proteínas, vitaminas, antibióticos, vacinas, a partir da chamada "tecnologia do DNA recombinante”. A pesquisa down-stream é, portanto, uma fase em que a pesquisa encontra-se mais consolidada, seu campo de aplicação é mais definido, seus resultados podem ser utilizados para o desenvolvimento de novos medicamentos ou até mesmo em uma série de tratamentos dado seu alto potencial de industrialização. Assim, é possível compreender porque, no âmbito da propriedade intelectual, o autor propõe que os detentores dos resultados desse tipo de pesquisa não detenham o controle absoluto de sua patente de modo a permitir novas descobertas de utilidade pública. (N.T.)

41. Como ficou amplamente demonstrado pela experiência dos sistemas de saúde em todo o mundo, no início da década de 1990, com os diagnósticos do HCV [vírus da hepatite C], a recusa da Chiron de conceder a licença, desafiando simplesmente diagnósticos complementares do HCV, teve sérias conseqüências. Este nível de controle, ao mesmo tempo que é apropriado a tipos de invenções tradicionais mecânicas, de engenharia, elétricas ou até mesmo, em alguns casos, farmacêuticas, não é apropriado quando a área de demanda abrange exatamente o ingrediente do qual a saúde humana estava dependente. Ao mesmo tempo que não se pode subestimar o significativo benefício para a humanidade do trabalho científico que leva à clonagem e à determinação da seqüência do HCV, é preciso também reconhecer que uma grande parte do financiamento para aquele trabalho vem de recursos públicos. É preciso reconhecer também que, uma vez que as informações proporcionadas pela descoberta do HCV estavam tão fundamentalmente ligadas à saúde humana, foi obsceno tratá-las como qualquer outra mercadoria.

42. Ver a decisão de Madey v Duke University (2002) Case 01-1567 (CAFC) pronunciada em 3 de outubro de 2002 .

43. Cordell Hull foi secretário do Estado dos Estados Unidos entre 1933 e 1944.

\section{Referências bibliográficas}

BASKEER, S. Limiting the patentability of pharmaceuticals inventions and micro-organisms: a TRIPS compatibility review, nov. 2005.
CORREA, C. M. Implications of bilateral free trade agreements on acess to medicines. Bulletin of the World Health Organisation, n.84, p.399-404, 2006

CRESPI, S. Biotechnology patenting: the wicked animal must defend itself. EIPR, v.17, n.9, p.431-441, 1995

DRAHOS, P. Information Feudalism. New Press, 2003.

FINK, C.; MASKUS, K.(Ed.). Intellectual property and development. World Bank. Oxford University Press, 2005

GERVAIS, D. The TRIPS agreement, sweet \& maxwell, 2003, p.16/ 1.18

GRAHAM, E.; WADA,E. Foreign Direct Investment in China. In: DRYSDALE, P. (Ed.). Achieving high growth: experience of transitional economies in east asia, Oxford University Press, 2001.

HALLWARD-DRIMEIER, M. Do bilateral investment treaties attract foreign direct investment? Only a bit... and they could bite. The World Bank Development Research Group, Investment Climate, ago. 2003. Policy Research Working Paper, 3121

HULL, C. The memoirs of Cordell Hull, 1. New York: Macmillan, 1981.

KIRIN-AMGEN, Inc v Hoechst Marion Roussel Ltd (2004) All ER 286 (HL).

MIN, B. Trade and Foreign Direct Investment Patterns in the Republic of Korea in the Aftermath of the 1997 Asia Financial Crisis. Asia-Pacific Trade and Investment Review, v.2, n.1, maio 2006.

NEW, W. Divergences Slow Work of WIPO Traditional Knowledge Committee. Intellectual Property Watch, 12 dez. 2006.

Nuffield Council of Bioethics Discussion Paper, 2002, The Ethics of Patenting DNA, 26

Oxfam Briefing Paper, Signing Away The Future, p.5, mar. 2007

PALOMBI, L. The patenting of biological materials in the context of TRIPS. PhD Thesis, University of New South, Sydney. Disponível em: http://egkd.anu.edu.au/menus/ PDFs/PhDThesisFinal.pdf. Acesso em: set. 2004.

STEEN, K. Patents, patriotism, and "skilled in the art”, The History of Science Society, n.92 p.91-121, 2001

US\$33.9 billion of FDI settle in China in first half year, The China Daily, 13 jul. 2004.

USTR. Special 301 Report, Executive Summary, p.l, 2005

USTR. Report, Out-Of-Cycle Review Results - China, 2005

WADE, R. H. What Strategies Are Viable For Developing Countries Today? The WTO and the Shrinking of 'De- 
velopment Space', Review of International Political Economy, v.10, n.4, p.621-644, nov. 2003

WIPO Press Release PR/476/2007, 7 fev. 2007.

WORLD TRADE ORGANIZATION. Communication from the United States to the Council for TRIPS, IP/C/ W/469, 13 mar. 2006.
WORLD TRADE ORGANIZATION. Section D, Relationship of Genetic Resources and/or Traditional Knowledge to Invention, p. 7-8.

\section{Sobre o autor}

\section{Luigi Palombi}

Graduou-se em direito e economia pela University of Adelaide. Atuou como advogado na Austrália, especializando-se em direito de propriedade intelectual, com foco em leis de patente e biotecnologia. Foi parceiro da empresa de advocacia de patentes, Davies Collison Caves, e das empresas Michell Sillar, Palombi Hazan e Banki Palombi Haddock \& Fiora. Além disso, liderou a equipe do processo de patente da Murex contra Chiron sobre a patente do vírus hepatitis C, quebrando o domínio que a Chiron tinha sobre o genoma HCV em agosto de 1996. Em 1997, deixou de advogar na Austrália para se tornar consultor e conselheiro internacional de muitas empresas particularmente a respeito de patentes de biotecnologia e gene. Em 2004 entregou sua tese de doutorado que foi premiada pela University of New South Wales no ano seguinte. Em 2005, foi consultor da Minter Ellison, a maior firma de advocacia em patentes de biotecnologia da Austrália. Ele liderou e aconselhou equipes em litígios envolvendo patentes conduzidos em Cortes em várias jurisdições e perante o European Patent Office. Atualmente é conselheiro de várias organizações ao redor do mundo sobre patentes de gene e biotecnologia. Desde 2006, está à frente do Projeto de Direito de Sequência Genética (Genetic Sequence Right Project) na Australian National University. 